\title{
Antiplatelet Therapy and the Risk of Bleeding Induced by Gastrointestinal Endoscopic Procedures
}

\section{A Systematic Review of the Literature and Recommendations}

\author{
N.A. Kimchi, ${ }^{a}$ E. Broide ${ }^{a} \quad$ E. Scapa ${ }^{a} \quad$ S. Birkenfeld ${ }^{b}$ \\ a Institute of Gastroenterology, Liver Diseases and Nutrition, Assaf Harofeh Medical Center, Zerifin, Israel, \\ affiliated to the Sackler Faculty of Medicine, Tel Aviv University, Ramat Aviv, and bepartment of Gastroenterology, \\ Batyamon Medical Center, Clalit Health Services, Bat Yam, Israel
}

\section{Key Words}

Gastrointestinal endoscopy · Colonoscopy • Polypectomy • Endoscopic sphincterotomy $\cdot$ Gastrointestinal hemorrhage $\cdot$ Platelet aggregation inhibitors • Aspirin

\begin{abstract}
Antiplatelet drugs may increase the risk of bleeding induced by gastrointestinal endoscopic procedures. The antiplatelet effect of cyclooxygenase- 1 inhibitors lasts less than $4 \mathrm{~h}$. Skin and colonic bleeding times are prolonged for 3 and 5 days after aspirin and ticlopidine withdrawal respectively. Major bleeding from endoscopic biopsies is extremely rare. In the four recent largest series, the general incidence of polypectomy-induced major bleeding was $0.11-0.42 \%$. In more than half of the cases the bleeding was delayed, usually up to 2 weeks after the endoscopy. Although three retrospective studies suggested that aspirin does not increase the risk of polypectomy-induced bleeding, the power of these studies is limited. Similarly, it is difficult to draw conclusions from the two studies that assessed the risk of aspirin use during sphincterotomy. Aspirin withdrawal may be harmful in susceptible patients, mainly if it is for more than 7 days. There is no indication to stop aspirin before esophagogastroduodenoscopy, which may reveal aspirin-induced lesions. We rec-
\end{abstract}

ommend discontinuation of aspirin 4-7 days (according to the cardiovascular risk) before other endoscopic procedures. When aspirin is indicated for primary prevention, it can be resumed 14 and 10 days after polypectomy and sphincterotomy respectively. In cases of secondary prevention, it should be resumed after 1 week.

Copyright $\odot 2007$ S. Karger AG, Basel

\section{Introduction}

Gastrointestinal endoscopic procedures such as polypectomy or sphincterotomy carry uncommon but serious complications including hemorrhage. Antiplatelet drugs may increase the risk of bleeding induced by these procedures [1]. On the other hand, cessation of these drugs can be harmful especially in patients with known occlusive vascular disease [2]. Among guidelines published in 2002 by the American Society for Gastrointestinal Endoscopy (ASGE), it was stated that in the absence of a pre-existing bleeding disorder, endoscopic procedures may be performed in patients taking aspirin or other non-steroidal anti-inflammatory drugs (NSAIDs). The authors mentioned that this recommendation is based on limited published data [3]. Due to this lack of

\section{KARGER}

Fax +4161306 1234 E-Mail karger@karger.ch www.karger.com

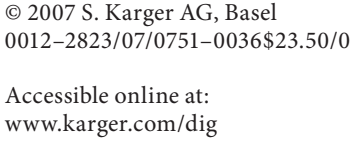

\footnotetext{
Dr. Nimrod Kimchi

Institute of Gastroenterology, Liver Diseases and Nutrition

Assaf Harofeh Medical Center

IL-70300 Zerifin (Israel)

Tel. +972 8977 9722, Fax +972 8923 0054, E-Mail nimrodK@asaf.health.gov.il
} 
adequate data, the use of antiplatelet drugs before gastrointestinal endoscopies is still controversial, even among endoscopists of the same medical center [4]. Our aims are: (1) to review the overall risk of bleeding from gastrointestinal endoscopic procedures, the risk of antiplatelet drugs in patients undergoing these procedures, and the risk of these drugs in patients undergoing non-gastrointestinal invasive procedures, and (2) to draw recommendations based on this review.

\section{Effect of Aspirin and Other Drugs on Platelet Function}

A single $100-\mathrm{mg}$ dose of aspirin irreversibly acetylates and inactivates the enzyme cyclooxygenase (COX) and thereby inhibits platelet production of thromboxane $\mathrm{A}_{2}$. Platelets, which are anucleate, cannot synthesize new enzymes and remain inactive for the rest of their lifespan. Aspirin prolongs the bleeding time (1.2-2.0 times) by blocking aggregation rather than adhesion. In contrast to aspirin, the effect of NSAIDs is reversible and generally short-acting $(<4 \mathrm{~h})$. COX-2 inhibitors do not directly affect platelets because COX-2 is absent in platelets. Furthermore, these drugs could be prothrombotic by inhibiting synthesis of prostacyclin by endothelial cells through a COX-2-dependent pathway.

The thienopyridines ticlodipine and clopidogrel $\left(\right.$ Plavix ${ }^{\circledR}$ ) primarily antagonize adenosine diphosphatestimulated platelet aggregation. They prolong the bleeding time test at least as long as aspirin. Furthermore, this prolongation may persist longer than with aspirin [1].

The effect of aspirin on colonic bleeding time was assessed in two studies. In one study, mucosal bleeding time, assessed by pinch biopsy in patients undergoing screening flexible sigmoidoscopy, did not differ significantly between the 90 control patients (had taken no aspirin or NSAIDs within the previous 2 weeks) and the 60 NSAID-using patients (received nabumetone $1 \mathrm{~g}$ b.d. by mouth for the previous 2 weeks). However, the 30 patients receiving aspirin (325 $\mathrm{mg}$ daily for the previous 2 weeks) exhibited significant prolongation of mucosal bleeding times [5].

In the other study, the authors developed an endoscopic device to make a standard incision (7-mm length) on the colonic mucosa. The colon bleeding time and skin bleeding time were measured before and $1 \mathrm{~h}$ after aspirin ingestion $(990 \mathrm{mg})$ in 10 healthy subjects. Significant prolongation was noted in both skin bleeding time $(\mathrm{p}<0.05)$ and colon bleeding time $(155 \pm 47$ vs. $244 \pm 169$ s, $p<$
$0.05)$ after aspirin ingestion. Two days were necessary for colon bleeding time to become normalized in patients after aspirin ingestion [6]. The same group later studied the effects of antiplatelet agents on quantitative skin bleeding times and platelet aggregation tests on 11 healthy men. Three days after cessation of aspirin $(100 \mathrm{mg} /$ day for 7 days), skin bleeding times (including blood loss volume) decreased to values which were not significantly different from the pre-administration values. In contrast to aspirin, 5 days after cessation of ticlodipine and 7 days after cessation of combined aspirin and ticlodipine administration, bleeding times where still slightly elevated, albeit the difference was not significant [7]. Similar findings were demonstrated on 100 patients undergoing elective cardiac surgery. Patients who ceased aspirin $\leq 2$ days preoperatively had weaker platelet aggregation responses $(18.5 \pm 7 \%$ maximum aggregation, mean $\pm S D, n=36)$ than patients who ceased aspirin 3-7 days preoperatively $(68.8 \pm 29 \%, \mathrm{n}=48, \mathrm{p}<0.001)$ or $>7$ days preoperatively $(68.3 \pm 28 \%, \mathrm{n}=16, \mathrm{p}<0.001)$. Assessment using the Platelet Function Analyzer collagen/epinephrine closure times yielded similar significant differences [8].

These findings suggest that aspirin withdrawal 3 days prior to a polypectomy may be sufficient. However, findings based on a 7-mm incision of the colonic mucosa may not be applicable to a large sessile polypectomy. Furthermore, skin bleeding time, which is dependent on technical variability, is not entirely reliable and the platelet aggregation test results may remain abnormal for up to 1 week until affected platelets are replaced [9].

\section{Aspirin and the Gastrointestinal Mucosa}

Although chronic use of aspirin significantly increases gastrointestinal blood loss [10,11], it appears to be related primarily to inhibition of gastric and duodenal prostaglandin production [12]. Low-dose aspirin was associated with a high endoscopic prevalence of gastroduodenal erosions in two recent open prospective studies [13, 14]. In a large randomized controlled study on patients with osteoarthritis, low-dose aspirin did not significantly increase the 12-week cumulative incidence of peptic ulcer compared to placebo ( 7.3 vs. $5.8 \%$ respectively). However, aspirin caused a more significant increase in erosions than did placebo [15]. Therefore, elective esophagogastroduodenoscopy (EGD), performed after aspirin has been withdrawn, may miss important aspirin-induced lesions. 
Table 1. Biopsy-related bleeding requiring endoscopic intervention or hospitalization

\begin{tabular}{lll}
\hline & Sieg et al. [19] & Parra-Blanco et al. [18] \\
\hline Study design & Prospective (Germany) & Retrospective (Japan) \\
Study period & $1998-1999$ & $1995-1998$ \\
UGI endoscopies & 110,469 & NA \\
$\quad$ Biopsies & NA & NA \\
Biopsy-related bleeding & $2(0.002 \%)$ & NA \\
$\quad$ Major bleeding & NA \\
Colonoscopies & $1(0.001 \%)$ & 9,555 \\
Biopsies & 82,416 & NA \\
Biopsy-related bleeding & NA & $9(0.09 \%)^{2}$ \\
Major bleeding & $1(0.001 \%)$ & 0 \\
\hline & 0 & \\
NA = Not available. & & \\
${ }^{1}$ Major bleeding - requiring hospitalization. & \\
${ }^{2}$ Seven immediate and 2 delayed, successful endoscopic hemostasis. \\
\hline
\end{tabular}

\section{Types of Bleeding Induced by Gastrointestinal Endoscopy}

There are two types of bleeding induced by endoscopic biopsy or polypectomy:

(1) Immediate bleeding occurs during the endoscopic procedure and requires endoscopic intervention (e.g. adrenaline injection, cauterization, hemoclipping). This type of bleeding is usually due to inadequate coagulation of vessels during the polypectomy [16].

(2) Delayed bleeding occurs usually within the first 2 weeks after the colonoscopy, but has been reported to be delayed for even 29 days [17]. Bleeding that is thought to present when the eschar detaches from the polypectomy site is frequently major - necessitating hospitalization, blood transfusion and/or endoscopic intervention.

\section{Biopsy-Related Bleeding}

The risk of major bleeding from endoscopic biopsies seems to be extremely rare (table 1 ). In a retrospective study on 9,555 colonoscopies, 7 cases of biopsy-related immediate bleeding and 2 cases of delayed bleeding occurred, all were successfully treated endoscopically [18]. In a large prospective study, biopsy-related major bleeding occurred in only 1 of 110,469 EGDs and 1 of 82,416 colonoscopies [19].

\section{Polypectomy-Related Bleeding}

In older series, the incidence of polypectomy-induced bleeding was higher than in recent series. In the largest series from the 1970s (a survey among members of the American Society of Colon and Rectal Surgeons), bleeding occurred in $1 \%$ of the 7,393 patients who underwent a colonoscopic polypectomy [20]. In these series, most of the bleeding events were of the immediate type, probably because of the type of current used and/or missing many instances of delayed bleeding due to the studies' design [21]. Table 2 describes the risk of polypectomy-related bleeding in the four largest recent series. The policy regarding aspirin use and endoscopic practices (e.g. adrenaline injection before the polypectomy) were not mentioned in these studies. Among 6,393 patients who underwent a colonic polypectomy in two US hospitals, the rates of immediate major bleeding were $0-0.19 \%$, whereas the rates for delayed major bleeding were $0.23-0.36 \%[22$, 23]. Delayed major bleeding events occurred 1-16 days after the polypectomy in one study [22] and after 0-12 days in another study [24]. In a prospective study in Germany, the bleeding rates were much lower: Among 14,249 patients who underwent a colonic or upper gastrointestinal polypectomy in private clinics, the rates of immediate major bleeding and late major bleeding were 0.05 and $0.06 \%$ respectively. Similarly, they recorded only 4 $(0.005 \%)$ perforations requiring surgery, among 82,416 colonoscopies. The authors' explanation for these low rates was that the participants in their study were almost exclusively experienced gastroenterologists. Among the 37 polyps with polypectomy-related bleeding (including 
Table 2. Polypectomy-related bleeding in recent largest series

\begin{tabular}{|c|c|c|c|c|}
\hline & Sieg et al. [19] & Nelson et al. [22] & Rosen et al. [23] & Gibbs et al. [24] \\
\hline Study design & Prospective & Prospective & Retrospective & Retrospective \\
\hline Study period & $1998-1999$ & 1994-1997 & $1987-1991$ & $1989-1993$ \\
\hline Setting & $\begin{array}{l}\text { Private practices } \\
\text { (Germany) }\end{array}$ & $\begin{array}{l}\text { Hospital (USA) } \\
\text { asymptomatic men }\end{array}$ & Hospital (USA) & Hospital (USA) \\
\hline Patients with polypectomy & $\begin{array}{l}14,249 \\
\text { (incl. UGI polyps) }\end{array}$ & 1,672 & 4,721 & $\begin{array}{l}6,365 \\
\text { (incl. biopsy only) }\end{array}$ \\
\hline All major bleeding events & $16(0.11 \%)^{1}$ & $6(0.36 \%)^{1}$ & $20(0.42 \%)^{2}$ & $13^{3}$ \\
\hline Immediate bleeding (minor and major) & $28(0.20 \%)$ & NA & NA & NA \\
\hline Immediate major bleeding & $7(0.05 \%)^{1}$ & $0(0 \%)^{1}$ & $9(0.19 \%)^{2}$ & 0 \\
\hline Delayed major bleeding & $9(0.06 \%)^{1}$ & $6(0.36 \%)^{1}$ & $11(0.23 \%)^{2}$ & $13^{3}$ \\
\hline \multicolumn{5}{|l|}{ Mean number of days (and range) } \\
\hline after polypectomy & $(1-\mathrm{NA})$ & $(1-16)$ & NA & $8(0-12)$ \\
\hline Requiring surgery & $1(0.007 \%)$ & & $1(0.02 \%)$ & \\
\hline Bleeding-related mortality & $1(0.007 \%)$ & $0(0 \%)$ & $0(0 \%)$ & \\
\hline $\begin{array}{l}\text { UGI = Upper gastrointestinal. } \\
{ }^{1} \text { Requiring transfusion, hospitalization } \\
{ }^{2} \text { Requiring hospital admission. } \\
{ }^{3} \text { Patients who underwent biopsies only }\end{array}$ & $\begin{array}{l}\text { urgery. } \\
\text { included, therefore }\end{array}$ & rcentages were no & lculated. & \\
\hline
\end{tabular}

immediate minor bleeding) in the German study, 9 were sessile and 12 of the 28 pedunculated polyps were $>2 \mathrm{~cm}$ [19]. These data support other reports that the bleeding risk is related to the type and size of the polyp [23, 25-27]. It seems that adrenaline injection or use of a detachable snare before removal of large polyps reduces bleeding, mainly of the immediate type [27].

\section{Polypectomy and Aspirin}

Guidelines on the management of antiplatelet therapy in patients requiring endoscopic procedures were published in 2002 by the ASGE. The authors stated that limited published data suggest that aspirin and other NSAIDs in standard doses do not increase the risk of significant bleeding after EGD with biopsy, colonoscopy with biopsy, polypectomy or biliary sphincterotomy [3]. However, regarding colonic polypectomy, these guidelines were based on the only published study at that time [25]. This study (table 3) focused on delayed bleeding, assessed by a mailed questionnaire or telephone follow-up. 694 patients were included in the study (230 underwent EGD with biopsy and 464 underwent elective colonoscopy with biopsy or polypectomy). $46 \%$ of the 694 patients were taking aspirin or NSAIDs within 1 week before the endoscopy. Major bleeding occurred in 4 pa- tients only, 2 of them from the NSAIDs/aspirin group. The authors concluded that the risk of significant bleeding after biopsy or colonoscopy does not appear to be affected by the use of aspirin or other NSAIDs. We think that the power of this study is too small to draw this conclusion. Furthermore, minor self-limited bleeding (defined as traces of blood per rectum) occurred in 20/320 (6.3\%) patients taking aspirin/NSAIDs and 8/374 (2.1\%) control patients $(\mathrm{p}=0.009)$. Therefore, the authors mentioned in the end of their discussion that it is not unreasonable to discontinue use of these medications before colonoscopy.

Since the publication of the 2002 ASGE guidelines, two studies on aspirin and the risk of polypectomy-induced colonic bleeding have been published (table 3).

The first study [28] retrospectively reviewed colonic polypectomy in 1,657 patients in Hong Kong. Among these patients, 219 were taking aspirin or another NSAID during the week before colonoscopy. Six (16\%) of the 37 patients in the bleeding group and 213 (13.2\%) of the 1,620 patients in the non-bleeding group were taking aspirin or NSAIDs ( $\mathrm{p}=0.62)$. In contrast, $4(10.8 \%)$ of the 37 patients in the bleeding group and $13(0.8 \%)$ of the 1,620 patients in the non-bleeding group were taking warfarin $(\mathrm{p}<0.001)$. Multivariate analysis showed that warfarin use was an independent risk factor for bleeding with an odds ratio (OR) of 13.37 (95\% CI 4.10-43.65), in 
Table 3. Studies on aspirin/NSAID use prior to polypectomy

\begin{tabular}{|c|c|c|c|}
\hline & Shiffman et al. [25] & Hui et al. [28] & Yousfi et al. [29] \\
\hline Study design & $\begin{array}{l}\text { Prospective (USA) } \\
\text { Delayed bleeding }\end{array}$ & $\begin{array}{l}\text { Retrospective (Hong Kong) } \\
\text { Immediate and delayed bleeding }\end{array}$ & $\begin{array}{l}\text { Case-control (USA) } \\
\text { Delayed bleeding }\end{array}$ \\
\hline $\begin{array}{l}\text { Patients and endoscopic } \\
\text { procedure }\end{array}$ & $\begin{array}{l}694 \text { ( } 230 \text { - EGD with biopsy; } \\
464 \text { - colonoscopy with } \\
\text { biopsy or polypectomy) }\end{array}$ & 1,657 (colonic polypectomy) & $\begin{array}{l}162 \text { (colonic polypectomy) } \\
\text { ( } 81 \text { - with major delayed bleed- } \\
\text { ing, } 81 \text { - control patients) }\end{array}$ \\
\hline Patients taking aspirin/NSAIDs ${ }^{2}$ & 320 & $\begin{array}{l}219 \text { (127 - aspirin only, } \\
85 \text { - NSAIDs, } 7 \text { - both) }\end{array}$ & Aspirin use only \\
\hline $\begin{array}{l}\text { Patients (\%) taking aspirin or NSAIDs } \\
\text { In bleeding group } \\
\text { In non-bleeding group } \\
\text { Significance }\end{array}$ & $\begin{array}{l}\text { NA } \\
\text { NA }\end{array}$ & $\begin{array}{l}6 / 37(16 \%)^{1} \\
213 / 1620(13 \%) \\
\text { NS }(p=0.62)\end{array}$ & $\begin{array}{l}32 / 81(40 \%) \\
27 / 81(33 \%) \\
\text { OR } 1.4 ; 95 \% \text { CI } 0.68-3.04\end{array}$ \\
\hline $\begin{array}{l}\text { Patients (\%) with major delayed bleedi } \\
\text { Among aspirin/NSAIDs users } \\
\text { Among control group (non-users) } \\
\text { Significance }\end{array}$ & $\begin{array}{l}\text { ing } \\
2 / 46(4.3 \%) \\
2 / 648(0.3 \%) \\
\text { NS }\end{array}$ & $\begin{array}{l}\text { NA } \\
\text { NA }\end{array}$ & $\begin{array}{l}\text { NA } \\
\text { NA }\end{array}$ \\
\hline $\begin{array}{l}\text { Patients (\%) with minor (traces of bloo } \\
\text { Among aspirin/NSAIDs users } \\
\text { Among control group (non-users) } \\
\text { Significance }\end{array}$ & $\begin{array}{l}\text { d) delayed bleeding } \\
20 / 320(6.3 \%) \\
8 / 374(2.1 \%) \\
p=0.009\end{array}$ & $\begin{array}{l}\text { NA } \\
\text { NA }\end{array}$ & $\begin{array}{l}\text { NA } \\
\text { NA }\end{array}$ \\
\hline
\end{tabular}

spite the fact that the mean INR was 1.41 only (range 1.11.87). Age, the location and size of the polyp and the use of antiplatelet agents were not associated with a higher risk of polypectomy-associated bleeding. In most of the patients $(\mathrm{n}=32)$, the bleeding was immediate and was treated successfully by endoscopic hemostasis in all cases. The more important type of bleeding, the delayed one, occurred in only 5 patients, a number which is too small for risk stratification.

The second study [29] indeed focused on the delayed type of postpolypectomy colonic bleeding. In this casecontrol study among 20,636 patients who underwent colonoscopy with polypectomy at Mayo Clinic institutions, $101(0.05 \%)$ patients presented with clinically significant postpolypectomy colonic bleeding. 20 patients were excluded from analysis because of prior anticoagulant use. The remaining 81 patients were matched (for age, gender and cardiovascular background) to $81 \mathrm{pa}-$ tients who had undergone colonoscopy without complications. The two groups were comparable in terms of polyp size $(97 \% \leq 10 \mathrm{~mm}$, bleeding group; $95 \% \leq 10 \mathrm{~mm}$, control group). Aspirin use prior to polypectomy was $40 \%$ in the bleeding group and $33 \%$ in the control group (OR 1.41; 95\% CI 0.68-3.04). The authors concluded that their findings supported the recommendations of the ASGE, stating that endoscopic polypectomy can be safely performed in patients taking aspirin. However, apart from the limitations of the case-control design and the reliability of the history of aspirin use, the authors mentioned that aspirin use after polypectomy was not addressed in their study. We think that this is the major limitation of this study. Use of aspirin was defined if taken within 3 days of colonoscopy. Bleeding occurred at a mean of 3 days (range $0-19$ ) after polypectomy. Thus, some of the bleeding events occurred when most of the patients' platelets were not exposed to the aspirin taken before the polypectomy. There is a possibility that after the polypectomy, patients in the bleeding group had resumed aspirin treatment more often than in the control group. In contrast to the Hong Kong study [28], there is no data regarding immediate bleeding in the Mayo Clinic study. Patients with immediate bleeding, even if it was 
minor, were possibly advised not to resume aspirin for a week or more after the polypectomy. Patients with both immediate bleeding (minor or major) and delayed bleeding were not described in the studies.

\section{Endoscopic Sphincterotomy and Aspirin}

The overall incidence of bleeding induced by sphincterotomy is $2.5-5 \%$ [30]. These variable rates reflect the definition of bleeding, for example in one study of 1,000 sphincterotomies, only 6 of the 39 bleeders were transfused and only 1 patient needed surgery [31]. Only two retrospective studies assessed the relative risk of antiplatelet use in patients undergoing endoscopic sphincterotomy. In the first study (1987-1991) [32], major hemorrhage occurred in 10 of 189 patients (5.3\%). Red blood cell transfusions (mean 9.9 units, range 2-19) were required in 7 patients. The other 3 patients had a hemoglobin drop of $3.4-5 \mathrm{~g} / \mathrm{dl}$. One patient, operated on to control bleeding, died. Bleeding onset was usually delayed (mean 3.0 days, range 0-9). By multivariate analysis, the three risk factors that predicted bleeding were hemodialysis (relative risk 8.4; 95\% CI 2.7-26.4), a prothrombin time prolonged at least $2 \mathrm{~s}$ above control (relative risk 7.8; 95\% CI 2.4-25.6), and endoscopically observed bleeding at the time of sphincterotomy (relative risk 5.9; 95\% CI 1.720.1). 50 of the 189 patients had taken aspirin or NSAIDs within 1 week prior to the sphincterotomy. Bleeding occurred in $5(10 \%)$ of them. The use of these drugs was not found to be a risk factor by multivariate analysis. We think that the safety of these drugs remains unproven because: (1) the power of this study is too small; (2) use of NSAIDs is relevant only if ingested a few hours before the sphincterotomy (maybe most bleeders were on aspirin and most non-bleeders were on NSAIDs?), and (3) overall, bleeding occurred primarily in patients with hemostatic defects including hemodialysis which was the strongest risk factor in this study. The bleeding tendency in patients with chronic renal failure is partly explained by uremia-induced altered platelet function [33].

In the second study (1990-2001) [34], 804 patients were recruited: 124 patients continued to take aspirin until the day of sphincterotomy (group 1), 116 patients had their aspirin discontinued for 1 week before sphincterotomy (group 2) and 564 control patients had never taken aspirin (group 3). Patients on NSAIDs were excluded from the study. The incidences of post-sphincterotomy bleeding in groups 1, 2 and 3 were 9.7, 9.5 and 3.9\%, and the incidences of delayed bleeding were 6.5, 6.9 and
$2.7 \%$, respectively. Only co-morbid illness and aspirin use were significantly associated with the development of bleeding by a logistic regression analysis $(p<0.001$ and $\mathrm{p}=0.04$, respectively). The authors conclude that although aspirin increased the risk of post-sphincterotomy bleeding, withholding aspirin for 1 week before the sphincterotomy did not seem to decrease the risk of this bleeding. Apart from the case-control design, this study has other limitations. Moderate or severe delayed bleeding occurred in only 3-4 patients in each of the three groups. The authors suggested that the persistent increased risk of post-sphincterotomy bleeding in patients in whom aspirin was withheld for 1 week before sphincterotomy may be partly due to the increased co-morbid illness in this group of patients and the lifespan of platelets. However, as we have already described, 7 days after aspirin withdrawal, most of the platelets are functional. The mean interval period between sphincterotomy and delayed bleeding, which was not mentioned in this study, was reported to be 3 days in other studies. Provided that aspirin was not administrated after the sphincterotomy, 10 days of withdrawal ensured that almost all platelets are functional [1, 5-9].

\section{Antiplatelet Therapy and Non-Gastrointestinal Invasive Procedures}

Due to the insufficient data regarding the safety of aspirin in patients undergoing upper gastrointestinal (UGI) or colonic polypectomy and sphincterotomy, it may be worthy to review shortly the significance of aspirin in non-gastrointestinal invasive procedures. In a case-control study, aspirin increased bleeding in the mother or neonate if it was ingested within 5 days before delivery. Aspirin ingested 6-10 days before delivery had no effect [35]. Some studies have shown that aspirin increases bleeding following coronary artery bypass surgery [36$38]$, although recent studies did not show this $[39,40]$.

In contrast to cardiac surgery, there is a lack of information regarding aspirin and abdominal surgery. In one study on a variety of surgical and gynecologic procedures, 12 (22\%) of 55 patients who had a positive drug history and abnormal platelet aggregation were judged to have excessive bleeding at surgery or postoperatively, compared with 7 (7\%) of 97 patients in the control group ( $p>0.02)$ [41]. The recommendations of the French Society of Anesthesiology and Intensive Care include the advice that aspirin should not be withdrawn for most vascular procedures; when a definite increase in intraopera- 
tive bleeding is feared, aspirin or clopidogrel can be replaced by NSAIDs for a 10-day period and interrupted the day before surgery; antiplatelet treatment should be resumed within $6 \mathrm{~h}$ after surgery [42].

Two studies assessed the risk of bleeding related to transrectal ultrasonography-guided prostate biopsies. In one study, 36 patients took aspirin before and after the biopsies whilst the other 141 did not. There was no significant increase in the incidence of hematuria or rectal bleeding among the aspirin users [43]. In the second study, even warfarin (49 patients) did not increase the frequency and severity of bleeding complications compared to the control group (731 patients) [44]. This is in contrast to the Hong Kong study [28] where warfarin use was found to be an independent risk factor for postpolypectomy bleeding (OR 13.4). Therefore, it may be inappropriate to draw recommendations regarding aspirin use and gastrointestinal procedures from procedures performed in areas other than the alimentary tract.

\section{Risk of Antiplatelet Withdrawal}

There is no doubt that cessation of antiplatelet therapy in patients with a recent coronary stent carries a significant risk $[45,46]$. However, two recent studies in France suggest that recent withdrawal of this therapy may be harmful in other patients with coronary artery disease. In one study, 1,358 consecutive patients admitted for a suspected acute coronary syndrome were followed for 30 days: 355 of them were users of antiplatelet drugs and 73 (aspirin, $\mathrm{n}=70$; ticlopidine, $\mathrm{n}=3$ ) had withdrawn these drugs (for scheduled surgery in 47 patients) $11.9 \pm 0.8$ days before admission. Recent withdrawers of antiplatelet drugs had higher 30-day rates of death or myocardial infarction $(21.9$ vs. $12.4 \%, p=0.04)$ than prior users. There was no difference between non-users and prior users. Multivariate analysis showed that withdrawal of antiplatelet drugs was an independent predictor of both mortality and bleedings at 30 days. Half of the withdrawers underwent substitution therapy, in the form of non-selective NSAIDs or low-molecular-weight heparin, which did not protect the patients [47]. The potential preventive effect of these NSAIDs, proposed by the French Society of Anesthesiology and Intensive Care in 2001 [42], is still unproved.

In another study, 1,236 patients hospitalized for acute coronary events were asked if aspirin intake had been interrupted. 51 of these events occurred within 1 month of aspirin withdrawal. Mean delay between aspirin with- drawal and the acute coronary event was $10 \pm 1.9$ days. Reasons for aspirin withdrawal included minor surgery or dental treatment in 20 cases, and endoscopy in 8 cases [48].

These two studies, by their design, obviously, were not able to assess the overall relative risk of coronary events after withdrawal of antiplatelet therapy. A prospective cohort study on this issue was performed on 19,283 cataract surgeries in patients of 50 years of age and older from nine centers in North America: $24.2 \%$ of patients routinely used aspirin and $22.5 \%$ of them discontinued the aspirin 14 days before surgery. There was no evidence of an increased risk of stroke, transient ischemic attacks or thromboembolic events among routine users who discontinued the use of aspirin (1.02/1,000 surgeries) compared with those who continued its use $(1.49 / 1,000$ surgeries). The relative risk of myocardial infarction or ischemia was 0.7 (95\% CI 0.1-5.9), comparing those who continued aspirin use with those who discontinued. However, due to the design of the study, which was not randomized controlled, a selection bias is possible. Those who were told to continue aspirin use may have been considered at higher risk of cardiovascular events than those who were allowed to discontinue medication before surgery. Therefore, rates of medical events among patients who stayed on aspirin might have been higher had they been required to stop this drug before surgery. There was no evidence that aspirin (and warfarin) use in this study increased the risk of ocular hemorrhagic events, supporting their continued use [49].

\section{Controversial Policies}

Due to the lack of available firm data, the policy regarding antiplatelet use before and after gastrointestinal endoscopies is controversial. A survey of ASGE members (1,269 questionnaires were analyzed) found that endoscopists stopped aspirin and NSAIDs more frequently before colonoscopy (81\%) and ERCP (79\%) than before UGI endoscopy (51\%). Only $20 \%$ performed sphincterotomy when aspirin and NSAIDs were not stopped compared to more than $85 \%$ and more than two thirds performing cold and hot biopsies respectively [50]. A structured case scenario on colonic polypectomy in an aspirin user was distributed to several members of the International Editorial Board of Gastrointestinal Endoscopy. One member believed that aspirin did not increase bleeding, another suggested discontinuing aspirin 5 days before polypectomy and the third member stated that in their unit, as- 
pirin was withdrawn 10 days before polypectomy and forbidden for 1 week afterwards. The editor commented that he requests discontinuation of aspirin 1 week before colonoscopy but still removes polyps if the patients have not complied with that request [51]. In Japan, cessation of antiplatelet therapy before endoscopic procedures is recommended [7]. Some authors suggest ceasing aspirin 7 days before any planned resection of large polyps or when multiple polypectomies are to be performed, and staying off aspirin for 2 weeks after piecemeal resection of large sessile polyps [52]. However, if we want to spare the patient the risk of a second colonoscopy, aspirin use should be ceased before any colonoscopy.

\section{Conclusions and Recommendations}

The safety of antiplatelet therapy in patients undergoing gastrointestinal endoscopic procedures remains unproved. Large multicenter randomized controlled studies are needed in order to draw firm conclusions. Meanwhile, based on the available data regarding the pharmacologic effects of antiplatelet drugs, including studies on colonic bleeding time, we propose the following recommendations:

\section{Diagnostic EGD}

There is no indication to stop aspirin before the endoscopy because: (1) although aspirin prolongs mucosal bleeding, the risk of biopsy-related major bleeding is extremely low (0.002\%); (2) most of UGI polyps are small, requiring biopsy only; (3) in the infrequent cases where a polypectomy is warranted, it can be performed during a second EGD, after aspirin withdrawal, and (4) EGD can reveal aspirin-induced mucosal lesions - an important finding in chronic aspirin users.

\section{Colonoscopy}

In many patients, it seems reasonable to stop aspirin before the procedure because: (1) the risk of polypectomy-related major bleeding is not negligible (up to $0.42 \%$ in recent series) and there is no sufficient data regarding the safety of aspirin use in this setting, and (2) in contrast to EGD, the prevalence of colonic polyps requiring removal is high and it is important to spare the patient the possibility of a second procedure if a polyp is found.

\section{Other Procedures}

Other procedures where it seems reasonable to stop aspirin before the procedure include: (1) endoscopic sphincterotomy; (2) esophageal dilation, and (3) endoscopic ultrasound-guided biopsy or drainage.

\section{Aspirin Withdrawal Period}

When aspirin is indicated for primary prevention, we recommend stopping this drug 5-7 days before colonoscopy. When the indication is secondary prevention, it is probably appropriate to shorten this period to 3 or 4 days. When a sphincterotomy is urgent (e.g. severe cholangitis) it should be made in spite of aspirin use if the prothrombin time is normal. When the procedure is less urgent (e.g. obstructive jaundice without cholangitis) it may be appropriate to perform the sphincterotomy 3-4 days after aspirin withdrawal.

In patients in whom the antiplatelet treatment is for primary prevention, we think that aspirin use should be avoided for 2 weeks after UGI or colonic polypectomy and 10 days after sphincterotomy. In others cases, the risk of delayed bleeding (e.g. by the polyp characteristics) and the cardiovascular risk of aspirin withdrawal should be assessed in order to define the management. When the cardiovascular risk is high, aspirin should be resumed probably no more than 1 week after the polypectomy.

If a patient has not complied with the request to withdraw aspirin before a colonoscopy, it is reasonable to remove polyps unless they are $>15 \mathrm{~mm}$, especially if sessile. After the procedure, this patient should be requested not to resume aspirin for 1-2 weeks, as mentioned above.

\section{NSAID Withdrawal Period}

Non-selective NSAIDs should be stopped $8 \mathrm{~h}$ before any endoscopy. After a polypectomy or sphincterotomy, it seems reasonable to not resume treatment with these drugs for 7-14 days. The use of COX-2 inhibitors carries no risk in this setting.

\section{Clopidogrel (Plavix $\left.{ }^{\circledR}\right)$ Withdrawal Period}

Based on the available limited information, we propose to stop clopidogrel, 5 days before colonoscopy. If the patient is with a recent coronary stent, it seems reasonable to postpone the colonoscopy if the indication is not urgent. 


\section{References}

1 Abrams CS, Shattil SJ, Bennett JS: Acquired qualitative platelet disorders; in Lichtman MA, Kipps TJ, Kaushansky, K, Beutler E, Seligsohn U, Prchal JT (eds): Williams Hematology, ed 7. New York, McGraw-Hill, 2006, pp 1833-1855.

-2 Patrono C, Garcia Rodriguez LA, Landolfi R, Baigent C: Low-dose aspirin for the prevention of atherothrombosis. N Engl J Med 2005;353:2373-2383.

-3 Eisen GM, Baron TH, Dominitz JA, et al: Guideline on the management of anticoagulation and antiplatelet therapy for endoscopic procedures. Gastrointest Endosc 2002;55: 775-779.

4 Hui CK, Lai KC, Yuen MF, Wong WM, Lam SK, Lai CL: Does withholding aspirin for one week reduce the risk of post-sphincterotomy bleeding? Aliment Pharmacol Ther 2002;16: 929-936.

5 Basson MD, Panzini L, Palmer RH: Effect of nabumetone and aspirin on colonic mucosal bleeding time. Aliment Pharmacol Ther 2001;15:539-542.

-6 Nakajima H, Takami H, Yamagata K, Kariya K, Tamai Y, Nara H: Aspirin effects on colonic mucosal bleeding: implications for colonic biopsy and polypectomy. Dis Colon Rectum 1997;40:1484-1488.

7 Komatsu T, Tamai Y, Takami H, Yamagata K, Fukuda S, Munakata A: Study for determination of the optimal cessation period of therapy with antiplatelet agents prior to invasive endoscopic procedures. J Gastroenterol 2005;40:698-707.

$\checkmark 8$ Gibbs NM, Weightman WM, Thackray NM, Michalopoulos N, Weidmann C: The effects of recent aspirin ingestion on platelet function in cardiac surgical patients. J Cardiothorac Vasc Anesth 2001;15:55-59.

-9 Hirsh J, Salzman EW, Harker L, et al: Aspirin and other platelet active drugs. Relationship among dose, effectiveness, and side effects. Chest 1989;95:12S-18S.

$\checkmark 10$ Steering Committee of the Physicians' Health Study Research Group: Final report on the aspirin component of the ongoing Physicians' Health Study. N Engl J Med 1989; 321:129-135.

$>11$ SALT Collaborative Group: Swedish Aspirin Low-Dose Trial (SALT) of $75 \mathrm{mg}$ aspirin as secondary prophylaxis after cerebrovascular ischaemic events. Lancet 1991;338:13451349.

-12 Cryer B, Feldman M: Effects of very low dose daily, long-term aspirin therapy on gastric, duodenal, and rectal prostaglandin levels and on mucosal injury in healthy humans. Gastroenterology 1999;117:17-25.

-13 Yeomans ND, Lanas AI, Talley NJ, et al: Prevalence and incidence of gastroduodenal ulcers during treatment with vascular protective doses of aspirin. Aliment Pharmacol Ther 2005;22:795-801.
14 Niv Y, Battler A, Abuksis G, Gal E, Sapoznikov B, Vilkin A: Endoscopy in asymptomatic minidose aspirin consumers. Dig Dis Sci 2005;50:78-80.

15 Laine L, Maller ES, Yu C, Quan H, Simon T: Ulcer formation with low-dose enteric-coated aspirin and the effect of COX-2 selective inhibition: a double-blind trial. Gastroenterology 2004;27:395-402.

-16 Van Gossum A, Cozzoli A, Adler M, Taton G, Cremer M: Colonoscopic snare polypectomy: analysis of 1485 resections comparing two types of current. Gastrointest Endosc 1992;38:472-475

17 Singaram C, Torbey CF, Jacoby RF: Delayed postpolypectomy bleeding. Am J Gastroenterol 1995;90:146-147.

18 Parra-Blanco A, Kaminaga N, Kojima T, et al: Hemoclipping for postpolypectomy and postbiopsy colonic bleeding. Gastrointest Endosc 2000;51:37-41.

19 Sieg A, Hachmoeller-Eisenbach U, Eisenbach T: Prospective evaluation of complications in outpatient GI endoscopy: a survey among German gastroenterologists. Gastrointest Endosc 2001;53:620-627.

20 Smith LE: Fiberoptic colonoscopy: complications of colonoscopy and polypectomy. Dis Colon Rectum 1976;19:407-412.

21 Lievens MW, Clement DJ: Another look at postpolypectomy hemorrhage. Am J Gastroenterol 1995;90:841-843.

22 Nelson DB, McQuaid KR, Bond JH, Lieberman DA, Weiss DG, Johnston TK: Procedural success and complications of large-scale screening colonoscopy. Gastrointest Endosc 2002;55:307-314.

23 Rosen L, Bub DS, Reed JF 3rd, Nastasee SA: Hemorrhage following colonoscopic polypectomy. Dis Colon Rectum 1993;36:11261131.

24 Gibbs DH, Opelka FG, Beck DE, Hicks TC, Timmcke AE, Gathright JB Jr: Postpolypectomy colonic hemorrhage. Dis Colon Rectum 1996;39:806-810.

25 Shiffman ML, Farrel MT, Yee YS: Risk of bleeding after endoscopic biopsy or polypectomy in patients taking aspirin or other NSAIDS. Gastrointest Endosc 1994;40:458462.

26 Sorbi D, Norton I, Conio M, Balm R, Zinsmeister A, Gostout CJ: Postpolypectomy lower GI bleeding: descriptive analysis. Gastrointest Endosc 2000;51:690-696.

27 Di Giorgio P, De Luca L, Calcagno G, Rivellini G, Mandato M, De Luca B: Detachable snare versus epinephrine injection in the prevention of postpolypectomy bleeding: a randomized and controlled study. Endoscopy 2004;36:860-863.

28 Hui AJ, Wong RM, Ching JY, Hung LC, Chung SC, Sung JJ: Risk of colonoscopic polypectomy bleeding with anticoagulants and antiplatelet agents: analysis of 1,657 cases. Gastrointest Endosc 2004;59:44-48.
29 Yousfi M, Gostout CJ, Baron TH, et al: Postpolypectomy lower gastrointestinal bleeding: potential role of aspirin. Am J Gastroenterol 2004;99:1785-1789.

30 Cotton PB, Lehman G, Vennes J, et al: Endoscopic sphincterotomy complications and their management: an attempt at consensus. Gastrointest Endosc 1991;37:383-393.

$>31$ Vaira D, D’Anna L, Ainley C, et al: Endoscopic sphincterotomy in 1,000 consecutive patients. Lancet 1989;ii:431-434.

32 Nelson DB, Freeman ML: Major hemorrhage from endoscopic sphincterotomy: risk factor analysis. J Clin Gastroenterol 1994;19:283287.

33 Noris M, Remuzzi G: Uremic bleeding: closing the circle after 30 years of controversies? Blood 1999;94:2569-2574.

34 Hui CK, Lai KC, Yuen MF, Wong WM, Lam SK, Lai CL: Does withholding aspirin for one week reduce the risk of post-sphincterotomy bleeding? Aliment Pharmacol Ther 2002;16: 929-936.

35 Stuart MJ, Gross SJ, Elrad H, Graeber JE: Effects of acetylsalicylic-acid ingestion on maternal and neonatal hemostasis. N Engl J Med 1982;307:909-912.

36 Ferraris VA, Ferraris SP, Lough FC, Berry WR: Preoperative aspirin ingestion increases operative blood loss after coronary artery bypass grafting. Ann Thorac Surg 1988;45: 71-74.

37 Sethi GK, Copeland JG, Goldman S, Moritz T, Zadina K, Henderson WG: Implications of preoperative administration of aspirin in patients undergoing coronary artery bypass grafting. Department of Veterans Affairs Cooperative Study on Antiplatelet Therapy. J Am Coll Cardiol 1990;15:15-20.

-38 Bashein G, Nessly ML, Rice AL, Counts RB, Misbach GA: Preoperative aspirin therapy and reoperation for bleeding after coronary artery bypass surgery. Arch Intern Med 1991; 151:89-93.

39 Mangano DT: Multicenter Study of Perioperative Ischemia Research Group. Aspirin and mortality from coronary bypass surgery. N Engl J Med 2002;347:1309-1317.

40 Bybee KA, Powell BD, Valeti U, et al: Preoperative aspirin therapy is associated with improved postoperative outcomes in patients undergoing coronary artery bypass grafting. Circulation 2005;112:I286-I292.

41 Kitchen L, Erichson RB, Sideropoulos H: Effect of drug-induced platelet dysfunction on surgical bleeding. Am J Surg 1982;143:215217.

42 Samama CM, Bastien O, Forestier F, et al: French Society of Anesthesiology and Intensive Care. Antiplatelet agents in the perioperative period: expert recommendations of the French Society of Anesthesiology and Intensive Care (SFAR) 2001 summary statement. Can J Anaesth 2002;49:S26-S35 
43 Maan Z, Cutting CW, Patel U, et al: Morbidity of transrectal ultrasonography-guided prostate biopsies in patients after the continued use of low-dose aspirin. BJU Int 2003;91: 798-800.

44 Ihezue CU, Smart J, Dewbury KC, Mehta R, Burgess L: Biopsy of the prostate guided by transrectal ultrasound: relation between warfarin use and incidence of bleeding complications. Clin Radiol 2005;60:459-463.

45 Popma JJ, Berger P, Ohman EM, Harrington RA, Grines C, Weitz JI: Antithrombotic therapy during percutaneous coronary intervention: the Seventh ACCP Conference on Antithrombotic and Thrombolytic Therapy. Chest 2004;126:576S-599S.
46 Kaluza GL, Joseph J, Lee JR, et al: Catastrophic outcomes of noncardiac surgery soon after coronary stenting. J Am Coll Cardiol 2000;35:1288-1294.

47 Collet JP, Montalescot G, Blanchet B, et al: Impact of prior use or recent withdrawal of oral antiplatelet agents on acute coronary syndromes. Circulation 2004;110:23612367.

48 Ferrari E, Benhamou M, Cerboni P, Marcel $\mathrm{B}$ : Coronary syndromes following aspirin withdrawal: a special risk for late stent thrombosis. J Am Coll Cardiol 2005;45:456459.

49 Katz J, Feldman MA, Bass EB, et al: Study of Medical Testing for Cataract Surgery Team. Risks and benefits of anticoagulant and antiplatelet medication use before cataract surgery. Ophthalmology 2003;110:1784-1788.
50 Kadakia SC, Angueira CE, Ward JA, Moore M: Gastrointestinal endoscopy in patients taking antiplatelet agents and anticoagulants: survey of ASGE members. American Society for Gastrointestinal Endoscopy. Gastrointest Endosc 1996;44:309-316.

51 Rutgeerts P, Wang TH, Llorens PS, Zuccaro G Jr: Gastrointestinal endoscopy and the patient with a risk of bleeding disorder. Gastrointest Endosc 1999;49:134-136.

52 Fraser C, Saunders B: Preventing postpolypectomy bleeding: obligatory and optional steps. Endoscopy 2004;36:898-900. 